\title{
A Catalytic Asymmetric Vinylogous Mukaiyama Aldol Reaction
}

\author{
Lars V. Heumann and Gary E. Keck \\ Department of Chemistry, University of Utah, 315 South 1400 East RM 2020, Salt Lake City, Utah, \\ $84112-0850$
}

\section{Abstract}

A vinylogous Mukaiyama aldol reaction, conducted using $10 \mathrm{~mol} \%$ of a BITIP catalyst and B $(\mathrm{OMe})_{3}$ as an additive, effects an enantioselective 4-carbon chain extension to give versatile $E-\alpha-\beta$ unsaturated thiolesters.

The Mukaiyama aldol addition is a powerful method for asymmetric C-C bond construction especially in the field of polypropionate natural product synthesis. Stereoselectivity is typically obtained through substrate control in additions to aldehydes bearing $\alpha$ - or $\beta$-stereocenters or through the control of a chiral catalyst in cases using a facially unbiased substrate or in order to override an inherent facial selectivity. ${ }^{1}$ A number of systems consisting of reactivitymatched nucleophile and chiral catalyst pairs have been developed for this type of addition, ${ }^{2}$ and several catalytic methods have also been established for the vinylogous version of this reaction. ${ }^{3}$

The asymmetric additions of several functionalized and unfunctionalized allylstannanes utilizing a selection of $\mathrm{BINOL} / \mathrm{Ti}(\mathrm{OiPr})_{4}$ (BITIP) systems, differing in the ligand to metal ratio and the method of preparation, have previously been developed in our laboratory. ${ }^{4,5}$ In addition to allylstannane additions, the BITIP system has also been used as an efficient catalyst in the addition of thiolester derived Mukaiyama reagents to aldehydes, giving rise to the products in high yield and excellent enantioselectivity. ${ }^{6}$ We were hopeful that we could extend these asymmetric Mukaiyama aldol reactions to encompass vinylogous cases, which would afford access to $\delta$-hydroxy- $\alpha, \beta$-unsaturated thiolesters, potential intermediates of interest with respect to structures such as preswinholide and acutiphycin (Figure 1). ${ }^{7}$

We investigated the use of this direct method employing diene 4 (Scheme 2). Although preliminary experiments using this reagent afforded good yields in additions to aldehydes using $\mathrm{BF}_{3} \cdot \mathrm{OEt}_{2}$ as Lewis acid, the use of reagent 4 in catalytic asymmetric additions using BITIP catalysis was not promising. Reactions using this reagent were far more sluggish than typical allylation reactions using this catalyst, and yields were lower. Aliphatic aldehydes required extended reaction times at $-20^{\circ} \mathrm{C}$ or ambient temperature (Table 1, entries 1 and 2). Reasonable results were obtained only with benzaldehyde. ${ }^{8}$ Nonetheless, the formation of addition products with reasonable enantiomeric ratios (ers) encouraged us to investigate means to increase the reactivity between aliphatic aldehydes and reagent $\mathbf{4}$ without sacrificing enantioselectivity.

A number of efforts have been made to gain insight into the mechanism of action of the BITIP catalyst system; $9,10,11,12$ however, an understanding of the exact role of each individual component remains elusive. In addition, seemingly subtle changes in the ligand-metal stoichiometry or method of catalyst preparation can have dramatic effects on the reaction 
outcome and some evidence for the formation of different catalytically active BITIP species has emerged. $4,5 \mathrm{~b}, 9,10,11$ Despite the complexity of these systems and lack of detailed understanding of catalyst structures, overall reaction mechanisms, and solvent effects, a number of additives and BINOL derivatives have been explored by several groups in an attempt to enhance the performance of the parent BITIP system. ${ }^{13}$ One of the additives used in combination with the original BITIP catalyst is $\mathrm{B}(\mathrm{OMe})_{3} 13 \mathrm{~b}$ which allowed for shorter reaction times while maintaining high yields and ers in reactions using allyltributylstannane as the nucleophile. ${ }^{13 b}$

Given this precedent, we decided to examine the effect of $\mathrm{B}(\mathrm{OMe})_{3}$ in the reactions of diene 4 with aliphatic aldehydes. After considerable optimization, reaction of diene $\mathbf{4}$ with hydrocinnamaldeyde 6 in the presence of $S$-BITIP (Method C) ${ }^{14}$ and $\mathrm{B}(\mathrm{OMe})_{3}$ in ether as solvent provided addition product 7 in $95 \%$ yield and with 93:7 er (Table 1, entry 11). Use of 0.5 equivalents of $\mathrm{B}(\mathrm{OMe})_{3}$ was established as the minimum amount necessary to achieve this reaction outcome; use of additional $\mathrm{B}(\mathrm{OMe})_{3}$ did not have any other observable effects. The configuration of the new alcohol was established to be ' $R$ ' by Mosher ester analysis; ${ }^{15}$ this is the configuration expected for a BITIP catalyzed addition using $S$-BINOL. ${ }^{4,5,6}$ In these experiments, reaction times were standardized at 4 days for comparison purposes.

Table 2 summarizes the yields and ers obtained for the catalytic asymmetric addition of diene 4 to several other aldehydes. Again, reaction times were standardized at 4 days, although most of the additions appeared to be complete within 2 days. Aliphatic aldehydes generally gave high yields coupled with good enantioselectivity. Although the yields for aromatic aldehydes were high, the enantioselectivity was slightly lower. The most surprising result is that enantioselectivity was essentially lost with an $\alpha, \beta$-unsaturated aldehyde, and the yield was also low (Table 2, entry 8). This stands in marked contrast to the allylation and Mukaiyama reactions, where the same substrate has been shown to afford $62 \%$ yield with $95: 5 \mathrm{er}^{4 \mathrm{~b}}$ and $76 \%$ yield with $95: 5 \mathrm{er}$, respectively. ${ }^{6}$

The reason for the beneficial effect of $\mathrm{B}(\mathrm{OMe})_{3}$ in this catalytic addition reaction is not obvious. A number of mechanistic possibilities in which $\mathrm{B}(\mathrm{OMe})_{3}$ could participate as part of a catalytic cycle before, during or after the addition can be envisioned. It has been suggested that $\mathrm{B}$ $(\mathrm{OMe})_{3}$ is simply a 'turnover-reagent' which facilitates the dissociation of the product from the reaction complex. ${ }^{13 \mathrm{~b}}$ Numerous other alternatives include the formation of a catalytically active BINOL/boron or bimetallic BITIP/boron complex, the formation of a vinylogous boron enol ether by transmetalation of $\mathrm{B}(\mathrm{OMe})_{3}$ with reagent 4 , and the generation of a reactive enolate through alkoxide assisted desilylation of reagent 4 . Another a priori possibility is that $\mathrm{B}(\mathrm{OMe})_{3}$ complexes oxygen in the BINOL ligand and enhances the Lewis acidity, and hence reactivity, of the BITIP catalyst.

In an attempt to develop an understanding as to the role of the various catalyst components, we conducted additonal experiments which employed NMR spectroscopy as a tool. A brief survey of deuterated solvents established $\mathrm{CDCl}_{3}$ as a suitable replacement solvent for ether in the preparation of the 'active' catalyst system (Table 3 ).

Unfortunately, ${ }^{11} \mathrm{~B}-\mathrm{NMR}$ offered little insight as to the role of $\mathrm{B}(\mathrm{OMe})_{3}$ in the catalytic cycle. However, the use of ${ }^{1} \mathrm{H}$-NMR gave some intriguing results. Here all spectra had to be taken after removal of the molecular sieves, otherwise, no useful spectra could be obtained. The spectra for three cases are summarized here: (a) The normal reaction protocol without added $\mathrm{B}(\mathrm{OMe})_{3}$, (b) the reaction protocol with added borate, and (c) the spectrum obtained when sieves are removed prior to addition of the borate.

While the signals in the ${ }^{1} \mathrm{H}-\mathrm{NMR}$ arising from BINOL and the ' $i \mathrm{PrO}$ ' methyl groups resulted in complex multiplets, the methyl of the ' $\mathrm{MeO}$ ' and the methine of the ' $i \mathrm{PrO}$ ' containing species 
were diagnostic. ${ }^{16}$ In the parent BITIP system, that is with no added $\mathrm{B}(\mathrm{OMe})_{3}$, all 'iPrO' exists in the "protonated form", that is, as isopropanol (Figure 3a). For the case when $\mathrm{B}(\mathrm{OMe})_{3}$ is present (and after the molecular sieves were removed) a minor fraction of the ' $i \mathrm{PrO}$ ' is still protonated; however the majority is bound to boron and another small fraction to titanium (Figure 3b). On the other hand, there is only a small signal corresponding to ' $\mathrm{MeO}$ '. When the molecular sieves were removed prior to addition of $\mathrm{B}(\mathrm{OMe})_{3}$, ' $i \mathrm{PrO}$ ' was found in equal amounts in the protonated form and bound to boron (Figure 3c); the ' $\mathrm{MeOH}$ ' signal, however, is large. These observations reveal a critical relationship between $\mathrm{B}(\mathrm{OMe})_{3}$ and the $4 \AA \mathrm{AS}$ in the $\mathrm{BITIP} / \mathrm{B}(\mathrm{OMe})_{3}$ system. We suggest that the $i \mathrm{PrO}$ groups observed on boron derive from exchange of free $i \mathrm{PrOH}$ with $\mathrm{B}(\mathrm{OMe})_{3}$. This exchange is facilitated by the presence of sieves (spectra $b$ vs. c). This reaction would liberate methanol, but essentially no methanol is observed if sieves are present (spectrum b). Hence the methanol is apparently sequestered by the $4 \AA$ MS. ${ }^{17}$ Hydrolysis of the methoxy borate by water contained in the sieves would also liberate methanol which would then be sequestered by the sieves. The ability of molecular sieves to act as a source of water and to facilitate the formation of titanium $\mu_{3}$-oxo species has previously been demonstrated. ${ }^{9}$

The function of the $4 \AA$ MS in this catalyst system is complex and also seems to extend beyond its role of capturing $\mathrm{MeOH} .9,10,11$ Reactions with diene $\mathbf{4}$ which parallel the procedures for catalyst preparation giving rise to spectra $\mathrm{b}$ and $\mathrm{c}$ above were also carried out. As expected, a low yield of addition product 9 was obtained when $\mathrm{B}(\mathrm{OMe})_{3}$ was added after removing the molecular sieves from the BITIP catalyst prepared according to method C (Table 4, entry 1), and enantioselectivity was also lowered. When $\mathrm{B}(\mathrm{OMe})_{3}$ was added before the molecular sieves were removed, a good chemical yield was obtained (Table 4, entry 2); however, the $e r$ was again below any of those measured for this addition in the presence of molecular sieves. These data suggest that participation of the $4 \AA$ MS is not limited to promoting formation of the active catalyst as in related systems, ${ }^{9}$ but that the $4 \AA$ MS may also play an important role during the progress of the reaction, as enantioselectivity is reduced significantly in their absence.

In summary, we have developed a new catalytic asymmetric Mukaiyama aldol addition with reagent 4 . We believe that this reaction will prove to be a valuable synthetic method given its success with aliphatic aldehydes coupled with the extreme ease of catalyst preparation from commercially available and inexpensive BINOL (ca. $\$ 0.70 /$ gram). In addition, our data reveal that the additive $\mathrm{B}(\mathrm{OMe})_{3}$ is not an unaffected participant in these reactions but in fact is consumed during catalyst formation.

\section{Supplementary Material}

Refer to Web version on PubMed Central for supplementary material.

\section{Acknowledgement}

Financial support was provided by the National Institutes of Health through Grant GM28961.

\section{References}

(1)(a). Evans DA, Dart MJ, Duffy JL, Yang MG. J. Am. Chem. Soc 1996;118:4322. (b) Mahrwald R. Chem. Rev 1999;99:1095. [PubMed: 11749441]

2. Machajewski TD, Wong Ch.-H. Angew. Chem. Int. Ed 2000;39:1352.

(3). (a) For recent reviews, see:Denmark SE, Heemstra JR Jr. Beutner GL. Angew. Chem. Int. Ed 2005;44:4682. (b) Kalesse M. Top. Curr. Chem 2005;244:43. (c) Casiraghi G, Zanardi F, Appendino G, Rassu G. Chem. Rev 2000;100:1929. [PubMed: 11749280] 
(4)(a). Keck GE, Krishnamurthy D, Roush WR, Reilly ML. Org. Synth 1998;75:12. (b) Keck GE, Geraci LS. Tetrahedron Lett 1993;34:7827. (c) Keck GE, Tarbet KH, Geraci LS. J. Am. Chem 1993;115:8467. (d) Keck GE, Krishnamurthy D, Grier MC. J. Org. Chem 1993;58:6543.

(5)(a). Heumann LV, Keck GE. Org. Lett 2007;9:1951. [PubMed: 17428064] (b) Keck GE, Yu T, McLaws MD. J. Org. Chem 2005;70:2543. [PubMed: 15787541] (c) Keck GE, Covel JA, Schiff T, Yu T. Org. Lett 2002;4:1189. [PubMed: 11922815] (d) Keck GE, Wager CA, Wager TT, Savin KA, Covel JA, McLaws MD, Krishnamurthy D, Cee VJ. Angew. Chem. Int. Ed 2001;40:231. (e) Keck GE, Yu T. Org. Lett 1999;1:289. [PubMed: 10822564]

(6). Keck GE, Krishnamurthy D. J. Am. Chem. Soc 1995;117:2363.

(7)(a). For a related asymmetric BITIP-mediated vinylogous Mukaiyama addition developed by Ian Paterson and coworkers, see:Paterson I, Findlay AD, Florence G. J. Org. Lett 2006;8:2131. (b) Paterson I, Florence GJ, Heimann AC, Mackay AC. Angew. Chem. Int. Ed 2005;44:1130. (c) Paterson I, Davies RDM, Heimann AC, Marquez R, Meyer A. Org. Lett 2003;5:4477. [PubMed: 14602029]

(8)(a). Krishnamurthy, D. Ph.D. Thesis. University of Utah; Salt Lake City, UT: 1995. Li, X-Y. Ph.D. Thesis. University of Utah; Salt Lake City, UT: 1998.

(9)(a). Mikami K, Matsumoto Y, Xu L. Inorg. Chim. Acta 2006;359:4159. (b) Terada M, Matsumoto Y, Nakamura Y, Mikami K. Inorg. Chim. Acta 1999;296:267. (c) Terada M, Matsumoto Y, Nakumara Y, Mikami K. Chem. Commun 1997:281. (d) Mikami K. Pure Appl. Chem 1996;68:639.

(10). Posner GH, Dai H, Bull DS, Lee J-K, Eydoux F, Ishihara Y, Welsh W, Pryor N, Petr S Jr. J. Org. Chem 1996;61:671. [PubMed: 11666990]

(11)(a). Balsells J, Davis TJ, Carroll P, Walsh PJ. J. Am. Chem. Soc 2002;124:10336. [PubMed: 12197736] (b) Davis TJ, Balsells J, Carroll P, Walsh PJ. Org. Lett 2001;3:699. [PubMed: 11259040] (c) Mori M, Nakai T. Tetrahedron Lett 1997;38:6233. (d) Zhang F-Y, Yip C-W, Cao R, Chan ASC. Tetrahedron: Asymmetry 1997;8:585.

(12)(a). Corey EJ, Lee TW. Chem. Commun 2001:1321. (b) Corey EJ, Letavic MA, Noe MC, Sarshar S. Tetrahedron Lett 1994;35:7553.

(13)(a). For a recent review on the use of BINOL as a metal ligand, see:Brunel JM. Chem. Rev 2005;105:857. [PubMed: 15755079] (b) Yu, Ch.-M.; Choi, H-S.; Yoon, S-K.; Jung, W-H. Synlett 1997:889. (c) Yu C-M, Choi H-S, Jung W-H, Kim H-J, Shin J. Chem. Commun 1997:761. (d) Yu, Ch.-M.; Choi, H-S.; Jung, W-H.; Lee, S-S. Tetrahedron Lett 1996;37:7095. (e) Mikami K, Matsukawa S. Nature 1997;385:613. (f) Matsukawa S, Mikami K. Tetrahedron: Asymmetry 1997;8:815.

(14). (a) For details of BITIP preparation according to methods A, B, C and D, see reference ${ }^{4}$. (b) Method A: Catalyst prepared from optically pure $\mathrm{BINOL}$ and $\mathrm{Ti}(\mathrm{O} i \mathrm{Pr})_{4}$ at $1: 1$ stoichiometry in the presence of $4 \AA \mathrm{MS}$ for $1 \mathrm{~h}$ at $38^{\circ} \mathrm{C}$. Method B: Catalyst prepared from optically pure BINOL and Ti $(\mathrm{O} i \mathrm{Pr})_{4}$ at $2: 1$ stoichiometry in the presence of $4 \AA \mathrm{MS}$ and $\mathrm{CF}_{3} \mathrm{CO}_{2} \mathrm{H}(0.003$ equiv relative to aldehyde) for $1 \mathrm{~h}$ at $38{ }^{\circ} \mathrm{C}$. Method $\mathrm{C}$ : Catalyst prepared from optically pure BINOL and Ti $(\mathrm{O} i \mathrm{Pr})_{4}$ at 2:1 stoichiometry in the presence of $4 \AA \mathrm{AS}$ for $1 \mathrm{~h}$ at $38^{\circ} \mathrm{C}$. Method D: Catalyst prepared from optically pure BINOL and $\mathrm{Ti}(\mathrm{O} i \mathrm{Pr})_{4}$ at $1: 1$ stoichiometry for $1 \mathrm{~h}$ at $25^{\circ} \mathrm{C}$.

(15)(a). Dale JA, Mosher HS. J. Am. Chem. Soc 1973;95:512. (b) Seco JM, Quiñoá E, Riguera R. Chem. Rev 2004;104:17.

(16). ' $i \mathrm{PrO}$ ' and 'MeO' designate the entirety of isopropoxide/isopropanol and methoxide/methanol species, respectively.

(17)(a). Fieser, LF.; Fieser, M. Reagents for Organic Synthesis. 1. Wiley; New York: 1968. p. 703 (b) Breck DW, Eversole WG, Milton RM, Reed TB, Thomas TL. J. Am. Chem. Soc 1956;78:5963. 


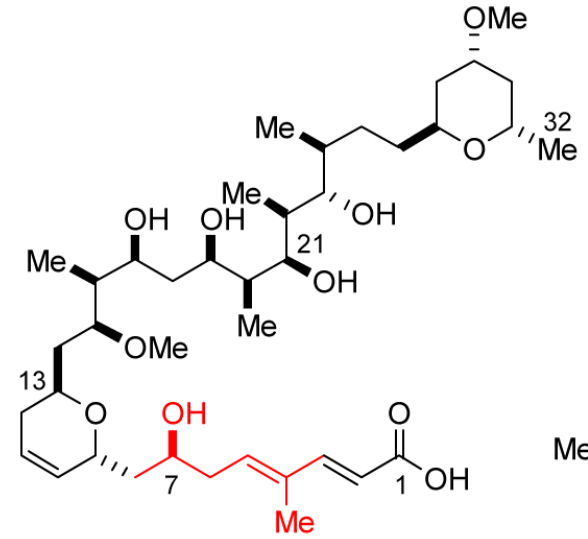

1 Preswinholide

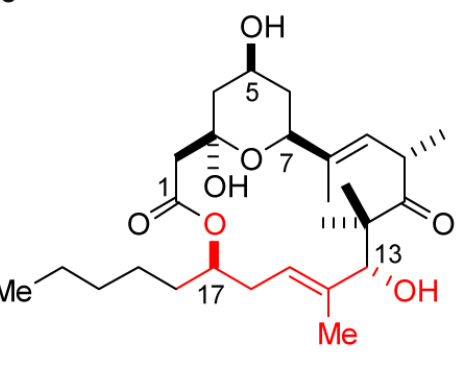

2 Acutiphycin

Figure 1.

Structures of Preswinholide and Acutiphycin. 


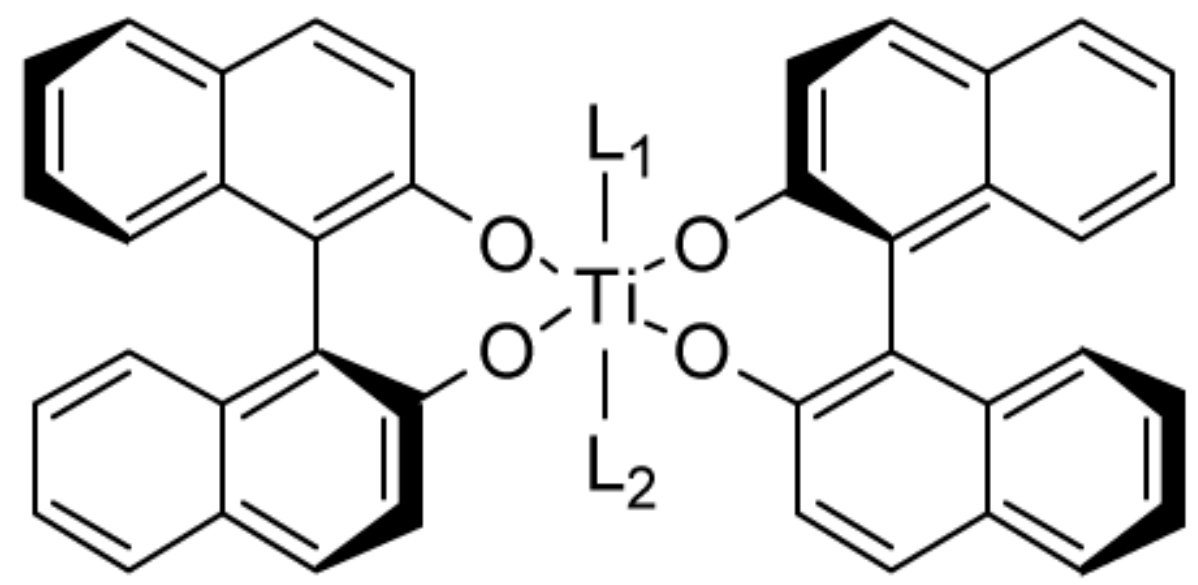

Figure 2.

Simplified Representation of an $S$-BINOL/Titanium Complex. 


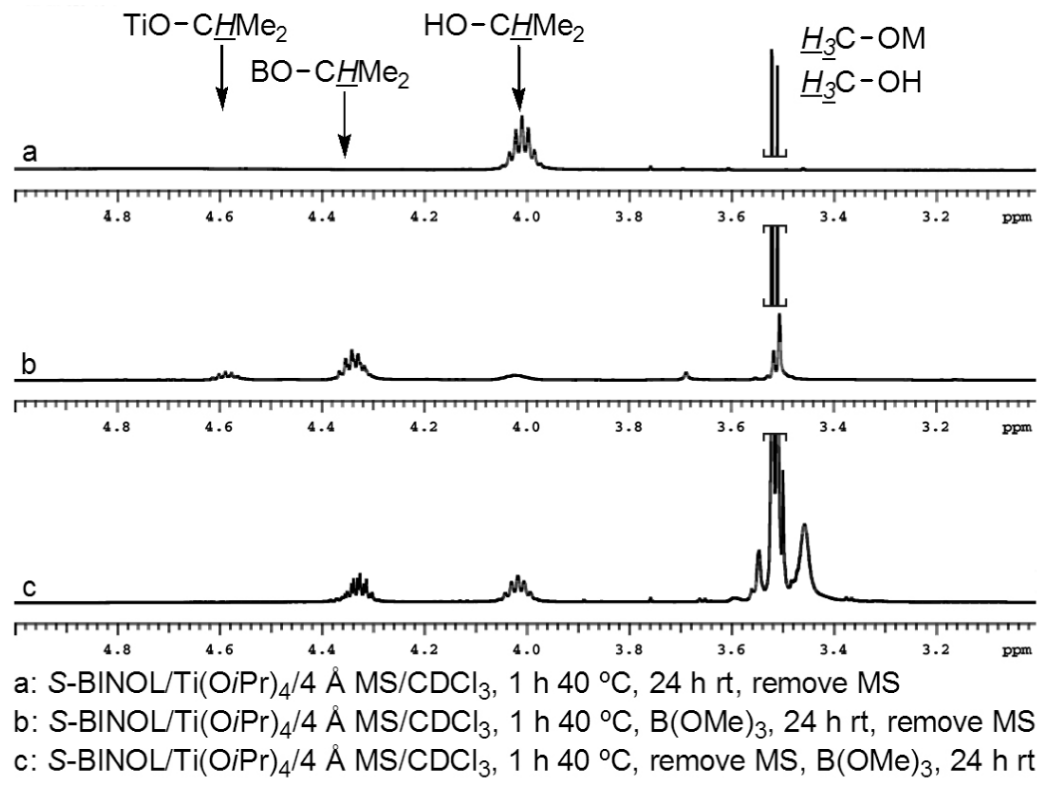

Figure 3.

Effect of Catalyst Preparation and Representative $300 \mathrm{MHz}{ }^{1} \mathrm{H}-\mathrm{NMR}$ Spectra. 


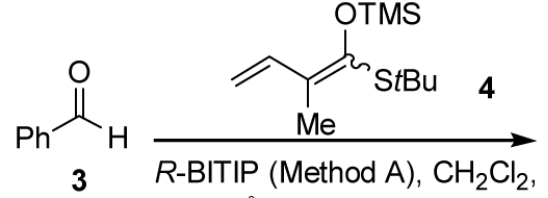

$4 \AA \mathrm{MS}, 6 \mathrm{~d},-20^{\circ} \mathrm{C}$

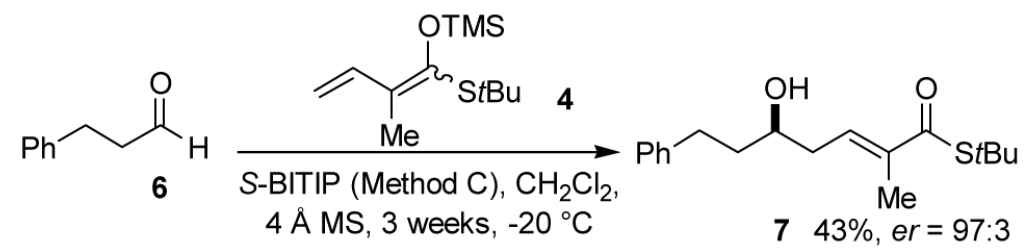

Scheme 2.

Initial Catalyst Controlled Additions using Reagent 4. 


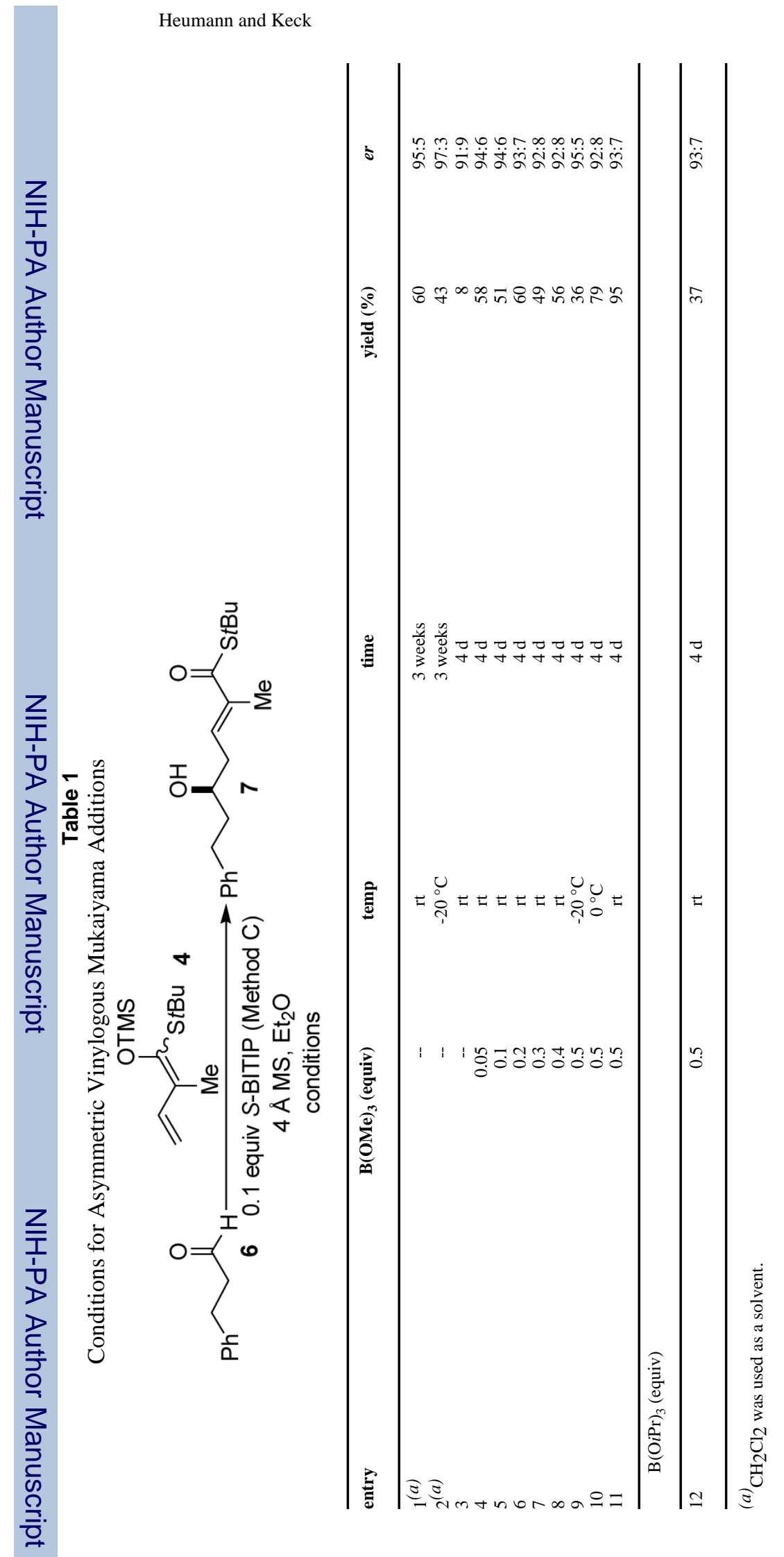

Page 9 
Table 2

Isolated Yields and ers for Asymmetric Vinylogous Mukaiyama Additions

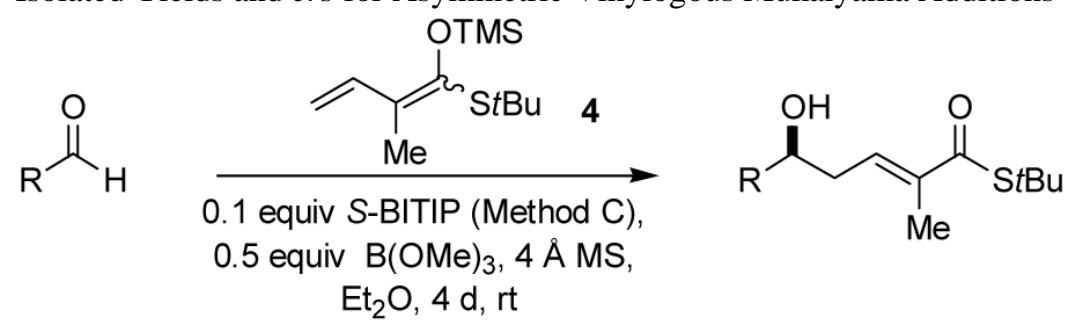

\begin{tabular}{|c|c|c|c|}
\hline entry & product & yield $(\%)$ & $e r^{(a)}$ \\
\hline 1 & & 90 & $95: 5$ \\
\hline 2 & & 97 & $96: 4$ \\
\hline 3 & & 92 & $95: 5$ \\
\hline 4 & & 93 & $92: 8$ \\
\hline 5 & $\mathrm{Me}$ & 95 & $93: 7$ \\
\hline 6 & & quant & $91: 9$ \\
\hline $7^{(b)}$ & & quant & $91: 9$ \\
\hline 8 & & 31 & $70: 30$ \\
\hline
\end{tabular}

(a) er determined by chiral HPLC.

(b) er determined by ${ }^{1} \mathrm{H}$ - and ${ }^{19}$ F-NMR analysis of the corresponding Mosher ester. ${ }^{15}$ 


\section{Table 3}

Isolated Yields and ers for Asymmetric Vinylogous Mukaiyama Additions in Ether and Selected Deuterated Solvents

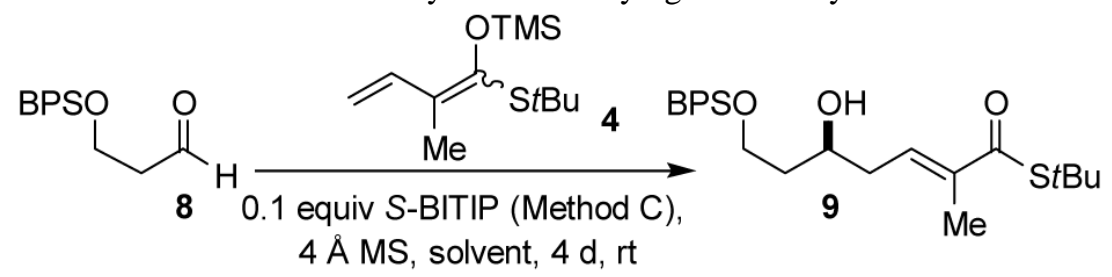

\begin{tabular}{llccc}
\hline entry & solvent & B(OMe) $)_{\mathbf{3}}$ (equiv) & yield (\%) & er \\
\hline 1 & $\mathrm{Et}_{2} \mathrm{O}$ & 0.5 & 97 & $96: 4$ \\
2 & $\mathrm{CD}_{2} \mathrm{Cl}_{2}$ & 0.5 & 55 & $76: 24$ \\
3 & $\mathrm{C}_{6} \mathrm{D}_{6}$ & 0.5 & 60 & $94: 6$ \\
$4(a)$ & $\mathrm{CDCl}_{3}$ & 0.5 & 61 & $97: 3$ \\
$5^{(a)}$ & $\mathrm{CDCl}_{3}$ & -- & $<20$ & $\mathrm{ND}$ \\
\hline
\end{tabular}

${ }^{(a)} \mathrm{CDCl}_{3}$ was filtered through a plug of alumina stored at $110{ }^{\circ} \mathrm{C}$ prior to use 


\section{Table 4}

Effect of Catalyst Preparation on Isolated Yields and ers for Asymmetric Vinylogous Mukaiyama Additions

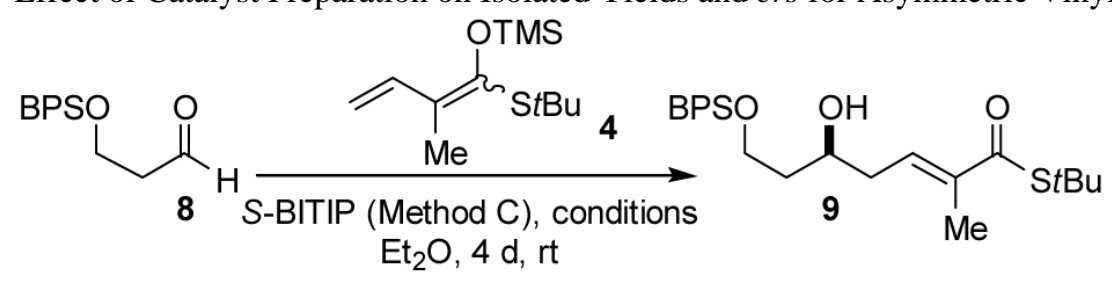

\begin{tabular}{|c|c|c|c|}
\hline entry & catalyst preparation & yield $(\%)$ & $e r$ \\
\hline 1 & $\begin{array}{l}S \text {-BINOL/Ti(OiPr })_{4} / 4 \AA \mathrm{MS} / \mathrm{Et}_{2} \mathrm{O}, 1 \mathrm{~h} 40^{\circ} \mathrm{C} \text {, remove } \mathrm{MS} \text {, add } \mathrm{B}(\mathrm{OMe})_{3}, 24 \mathrm{~h} \mathrm{rt} \text {, } \\
\text { add } 8 \text { and } 4\end{array}$ & 11 & $80: 20$ \\
\hline 2 & $\begin{array}{l}S \text {-BINOL/Ti }(\mathrm{O} i \mathrm{Pr})_{4} / 4 \AA \mathrm{MS} / \mathrm{Et}_{2} \mathrm{O}, 1 \mathrm{~h} 40^{\circ} \mathrm{C} \text {, add } \mathrm{B}(\mathrm{OMe})_{3}, 24 \mathrm{~h} \mathrm{rt} \text {, remove MS, } \\
\text { add } 8 \text { and } 4\end{array}$ & 90 & $87: 13$ \\
\hline
\end{tabular}

